\title{
As críticas de Augusto Comte à Economia Política
}

Gustavo Biscaia de Lacerda*

\section{Resumo}

O objetivo deste artigo é apresentar as críticas de Augusto Comte à Economia Política de sua época, bem como as propostas de reforma social daí advindas. $\mathrm{O}$ arcabouço metodológico consiste em categorias propostas pela História das Idéias, em particular por M. Bevir e Q. Skinner. O que poderíamos chamar de "teoria econômica comtiana" está presente na sua "Estática Social", na parte relativa à propriedade e aos elementos materiais da sociedade, e na sua "Dinâmica Social", no que se refere às inter-relações entre as mudanças políticas, sociais e econômicas ao longo da história. Essa teoria econômica dialoga tanto com os liberais quanto com os "comunistas", ao afirmar, por um lado, a necessidade da propriedade, mas também, por outro lado, a subordinação da propriedade às necessidades sociais e ao criticar severamente o individualismo. Daí resultam consequiências diretas e indiretas: por um lado, a sociedade não é redutível ao "mercado" e o Estado não pode ser omisso frente às flutuações econômicas; por outro lado, os conflitos de interesses mais imediatos de proletários e "patrícios" não podem ignorar a origem social da riqueza, sendo necessárias medidas morais e legais para regular e resolver esses conflitos. Nesse sentido, Comte é também um prenunciador do Estado de Bem-Estar Social ou, pelo menos, um teórico da justiça social.

Palavras-chave: Augusto Comte, Positivismo, Sociologia, crítica à Economia Política, holismo metodológico, justiça social.

* Doutorando em Sociologia Política na Universidade Federal de Santa Catarina (UFSC), sociólogo da Universidade Federal do Paraná (UFPR) e bolsista do Conselho Nacional de Desenvolvimento Científico e Tecnológico (CNPq). Endereço eletrônico: gblacerda@ufpr.br; gustavobiscaia@yahoo.com.br. 


\section{Introdução}

Em 2008 Philippe Steiner publicou um interessante artigo tratando Ede uma tradição da Sociologia francesa de crítica à Economia Política. Essa tradição começaria com Augusto Comte, o próprio fundador da Sociologia, passaria por Durkheim e pelos durkheimianos e chegaria, no fim do século XX, a Pierre Bourdieu; além disso, tal tradição constituir-se-ia de críticas teóricas e metodológicas aos procedimentos teóricos adotados pela Economia Política e, a partir disso, às consequiências práticas (i.e., sociais) das pesquisas econômicopolíticas. Essa tradição que Steiner apresenta serve como forma de recuperar alguns ancestrais - e, portanto, para legitimar intelectual e academicamente - a chamada Nova Sociologia Econômica, que, muito grosseiramente, afirma que a "economia" em si não existe, mas que deve ser socialmente situada e, assim, compreendida.

Não é nosso propósito questionar a correção de tal elaboração - mesmo porque concordamos com ela. O que nos interessa, particularmente, é apresentar os argumentos que o iniciador dessa tradição, bem como seus discípulos, utilizavam para contrapor-se à Economia Política. Assim, neste artigo veremos as concepções de Augusto Comte sobre os fenômenos econômicos e como eles inserem-se na concepção mais ampla de Sociologia que ele tinha; além disso, veremos algumas consequiências práticas das concepções teóricas anteriores, com as consequientes críticas à Economia Política.

Algumas palavras sobre os procedimentos metodológicos que adotamos e que nos orientam são interessantes. Consideramos algumas elaborações de dois expoentes da História das Idéias, Mark Bevir e Quentin Skinner. Elas não são completamente compatíveis entre si, mas permitem uma aproximação suficientemente grande para que, tomadas algumas precauções, sejam combinados proficuamente.

Assim, a primeira referência é a de Bevir (1999), que é a mais operacional das duas. Para Bevir, os intelectuais "maduros", isto é, aqueles que já passaram da fase formativa, pedagógica, e já produzem em termos intelectuais com autonomia, têm seus pensamentos formados a partir de várias tradições. Essas tradições são as várias fontes que informaram seus pensamentos ao longo do tempo: famílias, escolas, grupos políticos, sociais, religiosos e assim por diante; 
mesmo em cada um desses grupos pode haver mais de uma tradição (basta pensarmos no ambiente acadêmico ou na política, que se constituem pelos grupos em disputa). O pensamento de um pensador é sempre uma síntese original das várias tradições afluentes, muitas delas contraditórias entre si: o esforço de conciliação e de organização delas é que constitui a originalidade de cada pensador (e, no fundo, de cada ser humano) ${ }^{1}$.

Essa é a perspectiva estática; do ponto de vista dinâmico, Bevir sugere o conceito de "dilemas". Os dilemas são formulações que se diferenciam de maneira mais ou menos marcada do pensamento de cada um e a respeito do qual se apresenta uma necessidade de responder. Não se trata somente de negações do que cada um pensa, mas de perspectivas diferentes, em que o pensador tem que mobilizar os seus recursos intelectuais para concordar ou discordar delas, além de apresentar as infinitas gradações intermediárias entre a concordância total e a rejeição também total. No caso de concordar, o pensador tem que ajustar suas idéias para acomodar a nova perspectiva no seu interior, com todos os rearranjos necessários; no caso de discordância, é necessário mobilizar e articular as idéias para a contraposição com os argumentos opostos. É claro que a todo instante todos somos submetidos a novos dilemas, vindos dos mais variados lados, e temos que responder a eles também o tempo inteiro; a cada resposta - seja para acomodar, seja para discordar -, cada ser humano elabora uma nova síntese, que, portanto, nunca é imóvel ${ }^{2}$.

Por outro lado, Skinner (2002) considera que as idéias são instrumentos de disputa; assim como nas guerras manuseiam-se armas físicas, na política manuseiam-se argumentos, que são elaborados de acordo com a própria contenda. Como a política - isto é, as disputas - é inerente à sociedade, os argumentos elaborados

1 Bevir afirma que não há limites para a liberdade humana na elaboração de tais sínteses. Não concordamos com essa afirmação, pois há limitações pelo menos sociais e históricas para que o ser humano pense o que pensa. Todavia, como essa questão não é o objetivo deste artigo, não nos estendemos mais a seu respeito.

2 Bevir sugere a imagem de um lago, no meio do qual se joga uma pedra e que produz ondas que se espalham concentricamente. Os dilemas têm um efeito semelhante nas sínteses intelectuais individuais, pois eles provocam maiores reações - favoráveis ou não - nas regiões imediatamente próximas à questão disputada e que vão diminuindo à medida que se afasta desse epicentro. 
sempre integram disputas, ou seja, são feitos a partir dessas disputas para integrarem-nas. Evidentemente, essa perspectiva é adequada para uma pesquisa que enfatize a política da argumentação e suas relações com os conflitos políticos e sociais, mas não se pode levá-la demasiadamente longe, pois reduz todas as concepções humanas às disputas, deixando de lado ou menosprezando as elaborações substantivas (as crenças, em sentido amplo), as descrições da realidade, as elaborações mais ou menos "desinteressadas". Para dar um exemplo extremo e dificilmente discutível neste contexto, basta pensar-se em Os elementos, de Euclides: a qual disputa política ou social essa elaboração vincula-se? Assim, evitando o exagero de considerar a perspectiva de Skinner como aplicável a qualquer situação, o fato é que ela apresenta um evidente valor operacional.

Passemos, então, à apresentação dos argumentos de Comte.

\section{A Sociologia comtiana}

Apresentar os elementos básicos da Sociologia comtiana não é uma tarefa simples ou fácil. Isso devido a duas ordens de motivos: em primeiro lugar, como argumentou Juliette Grange (2000), se há um autor que elaborou um "sistema" de pensamento, esse autor é Comte. O que significa que a obra comtiana compõe um sistema? Não é apenas uma série de princípios e idéias que se encadeiam entre si, a partir de considerações a priori ou a posteriori como no caso de Descartes, mas, em um sentido muito mais forte, que todos os seus elementos relacionam-se com todos, de tal sorte que para explicar a importância relativa de uma concepção é necessário conhecer não apenas a lógica interna do sistema como também os demais elementos desse sistema. Ora, sendo a obra de Comte enciclopédica e enormemente erudita, buscando abranger todos os principais elementos da existência humana, tratar de um aspecto dela, em poucas páginas, é uma tarefa árdua.

Em segundo lugar, a despeito da reiterada afirmação de que Comte é um autor clássico da Sociologia, o fato é que sua obra é pouco ou nada conhecida, o que obriga os expositores a retomarem, cada vez que tratam dela, a sua lógica e seus argumentos mais importantes, não apenas para expor o que é necessário mas também para dirimir 
os mal-entendidos. Não há dúvida de que essa constante repetição, além de enfadonha, é motivo de desperdício de recursos e energia.

Dito isso, apresentemos tais elementos ${ }^{3}$. Antes de mais nada, é importante indicar que a elaboração comtiana visa a tornar positivas - isto é, científicas e humanas - as especulações sociais e morais: retirando essas especulações do domínio da teologia e da metafísica, é possível o ser humano perceber-se como um ser social, isto é, histórico e que vive apenas na e por meio da sociedade. Esse reconhecimento, além de permitir ao ser humano compreender melhor e mais completamente a sua própria realidade, também é o primeiro passo para aperfeiçoar essa mesma realidade. Dessa forma, Comte inclui-se na relação dos reformadores sociais do século XIX, que lançaram as bases do pensamento social contemporâneo a fim de intervir na sociedade ${ }^{4}$.

O caráter social - naturalmente social - do ser humano revelase com clareza e, no fundo, existe apenas por meio de seu caráter histórico: é a sucessão das gerações, cada qual com uma pequena contribuição para o conjunto da sociedade, que faz humano o ser humano. Essa historicidade conduz a um princípio ao mesmo tempo teórico e metodológico: a visão de conjunto é a que permite a positividade de vistas em todos os domínios, incluindo aí o social. Evidentemente, no que se refere à sociedade, a visão de conjunto pode assumir duas perspectivas: em um dado instante e ao longo do tempo. As diversas atividades humanas em um dado momento histórico produz a solidariedade, mas, como afirma e reitera Comte, é a continuidade histórica que caracteriza de fato o ser humano (cf. COMTE, 1980, v. III, p. 1-8).

Foi a partir da visão de conjunto histórica que Comte elaborou a sua lei dos três estados, que é o princípio fundamental do seu Po-

3 A apresentação que fazemos da obra de Comte considera a sua inteireza, isto é, além do Sistema de filosofia positiva (1830-1842), também e principalmente o Sistema de política positiva (1851-1854). Por motivos de concisão expositiva apresentaremos os argumentos e as idéias, sem nos preocuparmos em indicar, para cada questão, as referências bibliográficas específicas.

4 Disso já se torna claro que as correntes afirmações de que Comte era um pensador isolado em uma torre de marfim e cuja obra buscaria uma "objetividade" ou uma "neutralidade" asséptica já se revelam falsas. 
sitivismo. De acordo com ela, todas as concepções humanas passam por três fases: a teológica, a metafísica e a positiva. Na primeira, os fenômenos são explicados pelo recurso a vontades externas ao ser humano e arbitrárias: grosseiramente, são os deuses. Na fase metafísica os fenômenos são explicados por meio de abstrações personificadas, que no final das contas estabelecem círculos viciosos: por exemplo, o éter faz dormir devido às suas propriedades dormitivas. Quais são essas propriedades e por quais mecanismos elas funcionam não se sabe. Finalmente, no estágio positivo os fenômenos são explicados por meio das relações de semelhança ou de sucessão, isto é, por meio das leis naturais.

Algumas observações mais precisas:

1. a metafísica e a teologia compõem um grupo que se opõe à positividade devido ao seu caráter absoluto, que se revela não apenas em questões - irrespondíveis, no fim das contas - como "de onde viemos?" e "para onde vamos?”, como também pelo gênero de afirmações e perspectivas anistóricas e peremptórias; em oposição a elas, a positividade é relativa, fazendo perguntas passíveis de resposta (discutindo o "como" dos acontecimentos, não o seu "porquê") e respeitando a adequação de cada concepção humana relativamente à época e ao lugar em que foi feita (por exemplo: não faz sentido acusar os gregos e os romanos de crerem nos deuses se suas concepções eram ainda teológico-politeicas) (idem, cap. 1);

2. a metafísica tem um caráter de transição entre a teologia e a positividade, sendo ainda absoluta e afeita às vontades externas e arbitrárias, mas caminhando em direção à positividade. Dessa forma, ela assume uma condição crítica, isto é, destruidora: especialmente em termos de teoria social e política, a metafísica atua como solvente das concepções teológicas, mas é incapaz de propor, efetivamente, uma ordem social em seu lugar (ibidem);

3. a positividade não é a mera ciência. Augusto Comte apresenta uma série de motivos para essa diferença, mas uma bastante operacional para os nossos propósitos é a seguinte: enquanto a ciência é por definição analítica e 
intelectual, a positividade é sintética e abrange o conjunto da natureza humana (isto é, inteligência, sentimentos e atividade prática). Mais uma vez surge o tema da visão de conjunto: desta feita, a questão é determinar uma perspectiva sobre o ser humano que o considere em sua inteireza; todavia, a ciência é sempre parcial e fragmentária. Assim, a partir dos resultados da ciência (ou melhor: das diversas ciências), há que se elaborar uma síntese totalizante - síntese que é, necessariamente, filosófica (ibidem; cf. também COMTE, 1990);

4. como vimos, a natureza humana é tríplice (sentimentos, inteligência e ação prática): dessa forma, cada um desses aspectos exige sua satisfação própria ao longo da história e as sociedades procuraram diferentes maneiras de resolvê-las. Mais precisamente, cada instituição humana tem que levar em conta essa tríplice satisfação, o que inclui, obviamente, as relações econômicas (COMTE, v. I, cap. 3; v. II, cap. 2).

Uma última observação preliminar sobre a teoria de Comte. Sua Sociologia divide-se em Estática e Dinâmica, que correspondem aos elementos comuns a todas as sociedades e à sua evolução ao longo da história. Esses elementos são a religião (que não se confunde com a teologia), a família, a linguagem, o governo e a propriedade (idem): como veremos, as críticas de Comte à Economia Política situam-se na intercessão dos seus comentários à propriedade e ao governo.

\section{Comte e sua teoria econômica}

Steiner (2008) foi bastante preciso ao indicar dois elementos da crítica comtiana à Economia Política de sua época: por um lado, a origem metodológica dessa crítica; por outro lado, a submissão teórica dos fatores econômicos ao social e, assim, ao político. De maneira sucinta: para Comte, não é possível tratar os fenômenos econômicos de maneira desvinculada dos sociais (e - novamente - por extensão, políticos), de tal sorte que a "Economia Política" é sempre e necessariamente um capítulo específico da ciência geral da sociedade, a Sociologia. Tal inclusão do "econômico" no "social", 
derivada da perspectiva de conjunto, acarreta que é necessário entender os fenômenos materiais no corpo da Sociologia Estática e da Sociologia Dinâmica, ou seja, as leis relativas à produção, à transmissão e à circulação do capital relacionam-se intimamente às outras variáveis sociológicas, por um lado, e dependem do momento histórico em questão, por outro lado. Sabe-se que, durante o século $\mathrm{XX}$, o establishment acadêmico dedicado ao estudo da Economia, de modo geral estadunidense, mudou o nome de sua disciplina de "Economia Política" ("Political Economy") para, simplesmente, "Economia" ("Economics") para impedir a identificação dessa disciplina com o marxismo, não apenas com a perspectiva política marxista (revolucionária) como com a perspectiva teórica do marxismo, que é historicizante e, por assim dizer, sociologizante ${ }^{5}$. Na verdade, ao realizar sua elaboração econômica, Augusto Comte contrapõe-se não apenas contra os "economistas" de sua época, mas também contra os "comunistas", que, sem nenhuma casualidade, cometiam erros teóricos e práticos simétricos aos dos "economistas". Dessa forma, a fim de prosseguir, é necessário apresentarmos o que poderíamos chamar de "teoria econômica" comtiana.

Kremer-Marietti (1997) indicou de que maneira vários dos primeiros escritos de Comte - os chamados "opúsculos de juventude", redigidos entre 1817 e 1830 (quando publicou o volume I do Sistema de filosofia positiva ${ }^{6}$ ) -, fosse sozinho, fosse já como secretário de St.-Simon, tratavam do que chamaríamos contemporaneamente de "economia": orçamento público, relações financeiras e bancárias, teoria da produção e assim por diante. Esses artigos eram inspira-

5 Embora alguns autores afirmem a influência de Comte sobre o mainstream econômico - é o caso de Kremer-Marietti (1997), a propósito de elementos comtianos nas idéias (epistemológicas) de Milton Friedman -, isso não procede. Aliás, a distância que se guarda entre ambos é perceptível no livro de Mauduit (1929), que afirma ser A. Comte "autoritário" porque este, como veremos, desprezava a teoria do laissez-faire, considerando-a uma declaração de incapacidade teórica e uma irresponsabilidade prática.

6 O nome original dessa obra redigida em seis volumes ao longo de 12 anos era Curso de filosofia positiva (Cours de philosphie positive), cada capítulo correspondendo às lições do curso anual de mesmo nome que Comte iniciou a ministrar em 1826. Todavia, em nota de rodapé do Discurso sobre o conjunto do Positivismo (Discours sur l'ensemble du Positivisme), de 1848, ele alterou-o para "Sistema". 
dos, por um lado, pelo desejo de influenciar o debate público, no sentido de melhorar as condições de vida dos franceses; por outro lado, foram esforços iniciais para elaborar uma compreensão geral da realidade. $O$ guia teórico nesse empreendimento foi Jean-Baptiste Say - um dos poucos economistas que, depois, seriam elogiados por A. Comte-, cujas preocupações eram, até certo ponto, semelhantes às do fundador do Positivismo, no sentido de ter uma compreensão geral da realidade e que levasse em conta não apenas a perspectiva "material", mas também a social e a política; a diferença entre ambos é que Say era propriamente um economista que levava em consideração os elementos sociológicos, ao passo que Comte deseja criar uma Sociologia que compreendesse os elementos econômicos.

Do ponto de vista propriamente teórico, uma das considerações básicas de Comte, surgida nessa época, é sua oposição entre as sociedades militares e as sociedades industriais (cf. COMTE, 1972a; 1972b). As primeiras eram as próprias à Antiguiidade (clássica - grega e romana -, mas incluindo também as civilizações anteriores e exteriores a elas) e à Idade Média, caracterizando-se, do ponto de vista prático, pela preponderância da atividade militar (conquistadora na Antiguiidade, defensiva na Idade Média); a sociedade industrial é própria à modernidade ${ }^{7}$, isto é, ao período que se iniciou no século XIV e que se desenvolveu desde então ${ }^{8}$. A sociedade industrial, para Comte, caracteriza-se pelo conhecimento científico da realidade, pela prevalência das atividades pacíficas e pelo trabalho livre e organizado. Essa contraposição, na fase madura de Comte,

7 Aliás, a ligação entre a "sociedade industrial" e a "modernidade" foi afirmada por Anthony Giddens (GIDDENS \& PIERSON, 2000, cap. 1), que as toma por sinônimas. Em décadas anteriores, a "sociedade industrial" foi um conceito utilizado pela Sociologia para referir-se à organização econômico-política das sociedades contemporâneas de maneira alternativa a "capitalismo" (cuja origem, marxista, indica os comprometimentos políticos e ideológicos do conceito). Raymond Aron usou essa mesma expressão - em parte considerável no sentido comtiano - para, durante a Guerra Fria, referir-se à sociedade contemporânea, de modo a abranger tanto as sociedades democrático-capitalistas quanto as comunistas (cf., por exemplo, ARON, 1968).

8 Para Comte a modernidade inicia-se no século XIV, ou seja, quando o duplo movimento de destruição da ordem medieval (católico-feudal) e de constituição da ordem pacífico-industrial (positiva) tem início. Inversamente, para fins teóricos e didáticos, a Idade Média termina no século XIII (cf. COMTE, 1972a; 1972b). 
acabou tornando-se a "lei dos três estados da atividade prática", ou, mais precisamente, a oitava lei da "filosofia primeira", cujo enunciado é o seguinte: "A atividade é primeiro conquistadora, em seguida defensiva e enfim industrial” (COMTE, 1934, p. 479) ${ }^{10}$. Essa oposição pode ser sumariada da seguinte maneira:

QUADRO 1 - Comparação entre a Antiguidade, a Idade Média e a Modernidade

\begin{tabular}{|l|c|c|c|}
\hline ÂMBITO & ANTIGÜIDADE & IDADE MÉDIA & \multirow{2}{*}{ MODERNIDADE } \\
\hline \multirow{2}{*}{ Temporal } & \multicolumn{2}{|c|}{ Militar } & \multirow{2}{*}{ Pacífico-industrial } \\
\cline { 2 - 3 } & Conquistador & Defensivo & \\
\hline \multirow{2}{*}{ Espiritual } & \multicolumn{2}{|c|}{ Teológico } & \multirow{2}{*}{ Positividade } \\
\cline { 2 - 3 } & Politeico & Monoteico & \\
\hline
\end{tabular}

Fonte: o autor.

Essa oposição privilegia os elementos práticos da realidade: a política e a economia, para Comte, entram nessa categoria geral: as mútuas relações, indissociáveis, entre ambas, permitem afirmar-

9 As quinze leis da "filosofia primeira" são o conjunto de princípios teóricos e epistemológicos do Positivismo comtiano. Eles foram sistematizados por A. Comte na sua fase mais madura, isto é, ao longo da redação do Sistema de política positiva (1851-1854); seu nome - "filosofia primeira" - é uma evidente homenagem à proposta de Francis Bacon no sentido de organizar os princípios que organizam o conhecimento humano. Se a filosofia primeira são os fundamentos teóricos e epistemológicos do conhecimento, a "filosofia segunda" é o conhecimento da realidade propriamente dito e a "filosofia terceira" é a aplicação prática desses conhecimentos, ou seja, são respectivamente a ciência e a tecnologia. Entre inúmeras exposições e explicações dessas leis (algumas das quais de brasileiros), recomendamos a de Pierre Laffitte $(1894 ; 1928)$, que, embora rara de achar atualmente, é sem dúvida a melhor e merece não apenas uma nova edição francesa como uma (boa) tradução brasileira.

10 Para a boa compreensão dessa lei, ela deve ser lida e entendida particularmente em conjunto com a lei seguinte, que é a lei dos três estados da afetividade: "A sociabilidade é primeiro doméstica, em seguida cívica e enfim universal, segundo a natureza peculiar a cada um dos três instintos simpáticos [apego, veneração e bondade)" (COMTE, 1934, p. 479). Combinando-se as duas, o resultado é que os âmbitos afetivos da Antiguiidade e da Idade Média foram a família e a pátria, mas é próprio à modernidade a extensão dos sentimentos para o âmbito universal (é claro que sem deixarem de existir os âmbitos anteriores). 
mos que, para ele, a economia necessariamente era uma economia política - e vice-versa, no duplo sentido de que a organização e os elementos econômicos da sociedade produzem efeitos políticos e que muito da política passa pelas relações econômicas ${ }^{11}$. Mas o que devemos notar é que, após um início voltado para a economia política - de Say, Turgot e Dunoyer, mas acima de tudo Adam Smith e David Hume -, Comte logo desenvolveu a concepção de uma ciência geral da sociedade, de que a lei dos três estados é um primeiro resultado (e, na verdade, princípio fundador). Com essa concepção de ciência geral da sociedade, os elementos materiais teriam, sem dúvida alguma, grande importância, mas não seriam exclusivos nem por assim dizer determinantes. Por outro lado, como já vimos, a teoria totalizante é acompanhada de uma perspectiva metodológica igualmente totalizante e histórica, que rejeita o indivíduo como unidade de análise e como princípio metodológico.

Comte leu com atenção Adam Smith e reconheceu a importância do princípio da divisão do trabalho. Mas fê-lo com algumas particularidades: antes de mais nada, a divisão do trabalho não pode ser encarada apenas do ponto de vista econômico, isto é, não se trata de uma questão apenas de produtividade material, mas corresponde a um princípio geral da sociedade: muito antes (teórica e historicamente) de tratar-se de um princípio administrativo em fábricas, a divisão do trabalho estabelece que, na sociedade, alguns realizam trabalhos braçais, outros intelectuais, outros afetivos e assim por diante, sendo que a principal divisão é entre os trabalhos teóricos e os práticos. Em segundo lugar, para Comte a idéia da divisão do trabalho não se originaria com Adam Smith, mas seria possível deduzi-la do conjunto dos trabalhos de Aristóteles, na forma do seguinte aforisma: a sociedade consiste na separação dos ofícios e na convergência de esforços. Esse aforisma, por sua vez, estabelece que a sociedade baseia-se na especialização de tarefas, em que os indivíduos realizam voluntariamente atividades cada

11 Isso é tanto verdade que, para Comte, o poder (político) deve necessariamente caber aos detentores do poder econômico - sem que isso se degenere em uma plutocracia ou em uma oligarquia, graças às relações entre os poderes Temporal e Espiritual (cf. COMTE, 1852, cap. 2, 5, 6). 
vez mais específicas; mas, ao mesmo tempo, há que se ter uma visão de conjunto dessas atividades, para que elas sejam guiadas efetivamente para o bem comum e não se percam em esforços inúteis: a visão de conjunto caberia ao governo, seja material, seja espiritual ${ }^{12}$. Assim, em terceiro lugar, não há motivo algum para considerar que, no caso específico da atividade econômica, a divisão do trabalho corresponda a uma atividade puramente egoísta cujo resultado altruísta seria dado ao final por meio de uma propriedade metafísica. É claro que a economia é motivada pelo egoísmo - no mínimo todos temos que comer - mas somente isso não apenas não explica nada como também não permite, de fato, a existência da sociedade. $\mathrm{O}$ egoísmo tem que ser direcionado para fins altruístas, para o benefício da sociedade; já a divisão do trabalho, embora deva ocorrer em grande medida espontaneamente, deve ser observada com cuidado, a fim de satisfazer, efetivamente, necessidades sociais. No caso específico da economia moderna, há que se ter uma certa competição, que é de fato saudável, mas isso não equivale a uma atividade destrutiva e destruidora.

O que se depreende das observações acima é que a atividade econômica - representada pela divisão do trabalho - não é um fim em si mesmo, mas uma forma de alguns cidadãos satisfazerem as necessidades materiais da sociedade (enquanto outros satisfazem outras necessidades). Essa relação entre economia e sociedade, entre egoísmo e altruísmo pode ser explicada na análise que Comte faz da propriedade. A propriedade existe naturalmente, correspondendo a necessidades humanas elementares de alimentação, vestuário, moradia e trabalho. Embora ela possa ser coletiva - há inúmeras sociedades que se caracterizaram por essa modalidade de propriedade -, a sua eficiência é maior quando privada, isto é, quando um indivíduo concentra em suas mãos uma quantidade razoável de propriedade - o capital - e decide como utilizá-la. É claro que a concentração de capital nas mãos de um - ou de poucos - implica poder (político) para ele(s); mas, inversamente, esse poder implica

12 Como o próprio Comte reconhece, essa análise permite estabelecer com clareza a dinâmica social e os elementos fundamentais de toda teoria política (a sociedade civil e o Estado) (COMTE, 1890, v. II, cap. 5). 
responsabilidade. Do ponto de vista histórico, a propriedade começa a existir para satisfação de necessidades urgentes, o que, associado ao absolutismo teológico, torna a própria propriedade privada algo absoluto e indiscutível. Entretanto, como a sociedade é mais a continuidade histórica que a solidariedade em um momento, com o passar do tempo, isto é, das gerações, ocorre o acúmulo do capital e essas necessidades diminuem em sua urgência, de tal sorte que o egoísmo torna-se menos imperioso - o que equivale a dizer que o altruísmo passa a ter espaço. Somando-se a isso, no caso da sociedade industrial, que é pacífica e movida por um espírito relativo, a propriedade pode assumir um caráter diretamente social: a partir disso, mantendo a propriedade privada, isto é, o controle e a responsabilidade individuais pela propriedade, Comte elabora a máxima: "o capital é social em sua origem e deve sê-lo em sua destinação". Uma outra forma de entender essa fórmula é a seguinte: o capital deve ser utilizado para benefício coletivo, não podendo ser nem inútil (ou ocioso) nem se conferindo a ele o direito de "usar e abusar"; em outras palavras, para Comte a propriedade não é absoluta.

A esse respeito, Comte (1890, v. II, p. 141-148) sugere um experimento mental para desenvolver esse tópico: imaginemos que o ser humano fosse um ser apenas afetivo e intelectual, isto é, que não tivesse que satisfazer necessidades práticas: em tal caso, os instintos egoístas mais fortes (nutrição, sexual, materno, destruidor, construtivo) não seriam tão fortes ou seriam simplesmente fracos; o ser humano poderia desenvolver largamente sua existência altruísta. A ciência, por outro lado, embora tenha um aspecto de satisfação de curiosidade a respeito do mundo, não seria tão imperiosa, pois o ser humano não seria tão exigido do mundo para existir: em vez de a inteligência dedicar-se ao conhecimento da realidade, poderia dedicar-se diretamente à idealização da existência e a satisfazer os instintos altruístas. Em outras palavras, inexistente a pressão material sobre o ser humano, a Humanidade poderia ser diretamente altruísta e artística ${ }^{13}$.

13 Esse raciocínio - que é tão bonito e inspirador quanto filosoficamente perspicaz - foi chamado pelo sociólogo francês Pierre Arnaud de "a era dourada da humanidade" (ARNAUD, 1965). 
Caráter histórico, perspectiva totalizante, utilidade social, mudança do perfil do capital ao longo da história: Comte sintetiza essas características em suas duas leis econômicas, que se referem à produção econômica: 1) cada ser humano é capaz de produzir mais do que consome; 2) os produtos materiais humanos podem conservar-se por mais tempo do que exige sua conservação (idem, p. 150-154).

Para concluir esta seção, mais dois temas específicos. Em primeiro lugar, é importante notar que Augusto Comte não dissociava, sob hipótese alguma, o poder da responsabilidade: maior poder implica maior responsabilidade, isto é, maiores deveres e maiores cobranças. Isso vale tanto para os detentores do poder político - a quem, por definição, cabe o que chamamos atualmente de accountability - quanto para os detentores do poder econômico, cuja responsabilidade não consiste em usufruir das riquezas a bel-prazer, mas em serem gestores do capital social (ou melhor: do capital coletivo), que deve ser conservado e desenvolvido não apenas para a geração a que os gestores pertencem, mas para todas as gerações futuras (cf. COMTE, 1899, p. 43-46) ${ }^{14}$. Nesse sentido, Comte criticava a oposição privado-público, que, tornada absoluta, abria espaço para a irresponsabilidade coletiva dos particulares; ao mesmo tempo, afirmava que, todos concorrendo para o bem público, todos devem ser vistos como verdadeiros "funcionários públicos" (o que, aliás, apenas uma interpretação estreita e/ou malinformada pode considerar equivalente a "servidores do Estado" ou "integrantes do Estado total”) (cf. LACERDA, 2008).

Em segundo lugar, como tratamos até aqui da produção e um tanto da conservação do capital, talvez algumas palavras sobre a transmissão do capital sejam interessantes. Comte distingue quatro modos de o capital ser transmitido; de acordo com uma dupla ordem de dignidade decrescente e de surgimento histórico, são eles a dádiva, a troca, a herança e a conquista. A conquista era a

14 O discípulo de Comte, Pierre Laffitte, chega a literalmente afirmar que a preocupação com a transmissão do capital das gerações atuais para a posteridade tem que incluir a preservação do planeta Terra - o que chamaríamos de ambientalismo (cf. LAFFITTE, 1876)! 
modalidade característica da Antigüidade, ou, de modo mais geral, das sociedades militares; na sociedade industrial cabem apenas as outras três. A troca é um mecanismo usual e, entre as nações, deve ser incentivado o livre-comércio - desde que não prejudique as nações menos desenvolvidas. A herança, por sua vez, é a transmissão do capital entre um indivíduo que morre e outro que ainda vive: a escolha do destinatário pelo moribundo deve ser livre, de acordo com os critérios de capacidade administrativa do capital (o que vale tanto para o capital econômico quanto para os demais tipos de capital e também para o mando político ${ }^{15}$ ). A dádiva (don), para Comte, tem uma origem teológica, mas é a mais digna de todas as formas de transmissão do capital - superior, portanto, à troca e à herança - e cujo emprego deve ser sistematizado pelo Positivismo (COMTE, 1890, v. II, p. 155-156; cf. também LAFFITTE, 1876, p. 66-70) ${ }^{16}$.

\section{As limitações da Economia Política}

Para tratarmos das críticas de Comte à Economia Política de sua época, é necessário sabermos qual era essa Economia ou, pelo menos, a quais autores ele fazia referência. Assim, notamos à partida que Steiner (2008, apêndice 2) está correto ao afirmar que as referências comtianas, nesse assunto, eram basicamente francesas (Say, Turgot, Dunoyer, além de Quesnay e Colbert) mais Adam Smith; todavia, falta acrescentar David Hume e, embora pareça um tanto anacrônico, também Aristóteles.

Como vimos na seção anterior, Comte começou sua carreira próximo aos "economistas", em seu esforço de conciliar a constituição de uma ciência da sociedade com a intervenção política; todavia, em virtude das limitações teóricas, metodológicas e prá-

15 Sobre essa questão, cf. Lacerda Neto (2003).

16 Enfatizemos: Comte dizia isso pelo menos desde 1852, ou seja, setenta anos antes de Marcel Mauss e quase 150 anos antes do Movimento Anti-Utilitarista nas Ciências Sociais ("MAUSS")! Assim, a afirmação moral e social da dádiva, assim como diversas outras perspectivas, fazem de Comte um autor muito mais contemporâneo e "progressista" do que se pretende ou do que se sabe, de maneira alguma apóstolo do capitalismo, da exploração do proletariado etc. 
ticas da Economia, ele seguiu adiante, em direção à constituição da Sociologia, cujo marco, na biografia comtiana, foi 1822, com a descoberta da lei dos três estados e a redação do Plano dos trabaIhos científicos necessários para a reorganização da sociedade (COMTE, 1972c) ${ }^{17}$ - longo artigo que foi inicialmente intitulado Sistema de política positiva e cujo título seria recuperado três décadas mais tarde. Por que essa observação é importante? Porque esclarece que Comte, ainda que limitado aos autores franceses, estava familiarizado com as investigações econômicas de sua época.

Na segunda metade do Sistema de filosofia positiva, escrita entre 1838 e 1842, em que Comte trata propriamente da Sociologia, ele apresenta suas críticas aos economistas. Sua avaliação é dupla, positiva e negativa, ainda que os considere globalmente como metafísicos.

De maneira favorável, Comte considerava que os economistas tiveram uma importância teórica e outra prática. Teoricamente, eles introduziram as considerações materiais, especificamente econômicas, no âmbito das reflexões sociais: a importância do trabalho, da agricultura, do capital financeiro e dos bancos, a própria concepção de divisão social do trabalho: Adam Smith, David Hume, Jean-Baptiste Say, Dunoyer seriam tais pensadores. Politicamente, sua importância vincula-se à demonstração prática da inanidade dos esforços do Antigo Regime para reorganizar-se socialmente, ou, mais precisamente, da incapacidade de o Antigo Regime, vinculado a uma organização social e a uma teoria política anacrônicas, fazer

17 Foi essa busca que levou Comte a aproximar-se de St.-Simon, cujas preocupações eram bastante semelhantes. Todavia, as limitações teóricas e epistemológicas de St.-Simon, aliadas à sua volatilidade intelectual e, acima de tudo, às suas sérias falhas morais levaram Comte ao fim do relacionamento intelectual. Diga-se de passagem que os problemas científicos que Comte identificou nas idéias de St.-Simon são muito parecidas com as identificadas por ele no pensamento dos economistas. Por esse motivo, aliás, Comte desconsiderou a quase totalidade dos artigos de juventude, preservando apenas oito; os que ignorou são, não por acaso, justamente aqueles dedicados à Economia Política, seja teórica, seja prática. Cf. a respeito Gouhier (1936). Por outro lado, Paulo Carneiro e Pierre Arnaud recuperaram esses artigos renegados (incluindo aqueles escritos por A. Comte mas "assinados" por St.-Simon), o que permite termos uma compreensão mais acurada da evolução intelectual comtiana (cf. COMTE, 1970). 
frente às novas exigências sociais: Quesnay, Turgot e Colbert seriam os representantes desse aspecto da economia política ${ }^{18}$. Em outras palavras, os economistas foram importantes para a destruição prática do Antigo Regime e para a constituição teórica do novo regime (COMTE, 1975, p. 462: Système de philosophie positive, lição 55 ${ }^{\mathrm{e}}$ ).

Mas o fato é que a avaliação negativa merece muitos mais comentários que a positiva. Usando a edição francesa de 1975 da Filosofia positiva, vimos logo acima que os comentários favoráveis não ocupam nem uma página, enquanto as críticas ocupam seis longas páginas (idem, p. 92-97: Système de philosophie positive, lição $47^{\mathrm{e}}$ ). A extensão dessa crítica sugere a severidade com que Augusto Comte julga os economistas: considerando o capítulo em que estão esses comentários, torna-se compreensível tal rigor. Com efeito, a lição 47 é dedicada aos predecessores de Comte na constituição da Sociologia, entre os quais Aristóteles, Montesquieu, Condorcet e Bossuet - além dos economistas, tratados em conjunto como "seita". Por oposição, os outros comentários integram o capítulo dedicado ao movimento destruidor do Antigo Regime, isto é, dos "revolucionários" e dos "críticos" (entendidos, no sistema comtiano, como "destruidores"). Dessa forma, somando-se os comentários de um e de outro capítulo, resulta que a severidade de Comte a respeito dos economistas é que eles são mais danosos para a compreensão da sociedade e para reorganização social que positivos para isso; esses danos, como temos sugerido, são tanto teóricos quanto práticos.

A observação fundamental é que a Economia Política pretende constituir uma ciência - Comte repetidamente fala em "pretensa ciência" - à parte da Sociologia. Não se trata apenas de isolar, como um recurso lógico, os elementos econômicos dos demais elementos sociais e sociológicos: o procedimento da Economia é reduzir a sociedade às questões econômicas, o que equivale a desprezá-la e à Sociologia. Em vez de uma visão de conjunto, tem-se apenas uma

18 Desde já é interessante notar que, a despeito das críticas feitas à Economia Política de sua época, o respeito de Comte pelos personagens indicados era tal que foram todos eles incluídos, com as exceções de Say e Quesnay, no “calendário positivista” (cf. COMTE, 1996, p. 314-315). 
visão específica, tremendamente especializada. A ausência de uma visão de conjunto não ocorre apenas no nível analítico que chamaríamos hoje de "sincrônico" e a que Augusto Comte referia-se por meio da palavra "solidariedade"; essa especialização teórica também inclui (na verdade, inclui principalmente) o que poderíamos chamar de "presentismo", uma forma de anacronismo que, anos depois de Comte, seria igualmente criticada por Marx: a ilusão de considerar que as teorias da Economia Política são eternas e referem-se a todos os tempos e lugares. Por falta de visão de conjunto histórica e sociológica, os economistas ignoravam as diferentes formas de organização social, além das inúmeras interferências mútuas que os diversos elementos sociais mantêm entre si. Assim, não apenas as críticas feitas às formas anteriores ou não-ocidentais de organização sócio-econômica eram absolutas e, portanto, julgavam-nas incorretamente (cometendo anacronismos), como a realização do ser humano era reduzida às funções econômicas abstratas, em particular como produtor e como consumidor.

Comentamos acima que, para Comte, a Economia Política de modo geral era metafísica. Esse caráter metafísico era dado, por um lado, por sua função destruidora do Antigo Regime; por outro lado, também porque suas categorias eram simplesmente metafísicas, isto é, abstrações arbitrárias, absolutas (não-relativas) e vagas: "valor", "utilidade" e assim por diante não eram definidas com precisão nem baseadas em pesquisas históricas ou empíricas (sociológicas, em todo caso), mas propostas como que ex-nihil pelos economistas. Finalmente, o individualismo teórico e metodológico da Economia Política era um artifício teórico completamente arbitrário e injustificável para Comte: afinal de contas, a sociedade não é composta por indivíduos egoístas em busca da satisfação de seus interesses particulares, mas por famílias, pátrias e pela Humanidade, em que se estabelecem as mais diversas relações de acordo com o princípio de Aristóteles (separação dos ofícios e convergência dos esforços). Esse caráter metafísico assinalado por Augusto Comte aos economistas motivou sua caracterização - exceção feita a alguns poucos pensadores sérios, já indicados - como "seita de literatos", isto é, como um conjunto de repetidores medíocres e sem espírito científico (isto é, incapazes de atingirem o espírito positivo: relativo, histórico, altruísta etc.). 
Para Comte, a teoria serve como guia para a ação prática, via predição dos acontecimentos: ora, como a Economia via-se incapaz de fazer quaisquer previsões, sua utilidade prática era nula e, portanto, sua validade teórica também ${ }^{19}$. Mas, de maneira mais específica, o que os economistas afirmavam era que a realidade econômica constituía autonomamente uma ordem natural, em que se estabelecia um equilíbrio. Pois bem: enquanto para os economistas esse era o princípio e o fim da teoria e da prática - daí decorrendo a teoria do laissez-faire -, para Comte a ordem naturalmente constituída era apenas o princípio da elaboração teórica. Como vimos anteriormente, para Comte a sociedade constitui-se por meio da divisão do trabalho e pela convergência de esforços e era exatamente o segundo hemistíquio dessa fórmula que faltava aos economistas. Como a "convergência dos esforços" é responsabilidade do governo (isto é, dos poderes Temporal e, secundariamente, Espiritual), o que os economistas propunham é que o governo simplesmente não interferisse na dinâmica econômica - como se sabe, para o liberalismo econômico qualquer intervenção estatal é indevida, ainda que seja necessário um arcabouço institucional mínimo (justiça e manutenção da moeda). Mas, inversamente, para Comte - e para a Sociologia - a economia não existe per se, mas somente integrando uma realidade social mais ampla, socialmente constituída e condicionada. Ora, a doutrina do laissez-faire, do ponto de vista teórico, ignora essas mútuas relações ou considera-as "externalidades"; do ponto de vista prático, afirma que os problemas econômicos resolver-se-ão sozinhos, graças a uma propriedade qualquer que o sistema econômico apresentaria - a famosa e vulgarizada "mão invisível" - a longo prazo e independentemente de qualquer outra consideração sociológica, política ou mesmo moral, o que equivale à mais completa omissão política, especialmente do governo, responsável pela reação de conjunto social sobre as diversas partes constituintes. No meio dessas concepções, estariam implícitas ou explícitas 1) a apologia do egoísmo, 2) a afirmação cínica de que o altruísmo é uma forma hipócrita de justificar o egoísmo, 3) a postulação de que

19 Dessa forma, diferentemente do que afirma Steiner (2008), a crítica de Comte à Economia Política não era apenas teórica e metodológica, embora uma parte importante dela fosse-o, mas era também prática. 
a propriedade é absoluta e 4) a consideração de que o bem comum é no máximo a soma das utilidades particulares ${ }^{20}$.

Essas são as críticas de Comte, elaboradas em 1838 e repetidas mais ou menos até sua morte, em 1857. Se considerarmos os seguidores de Comte, veremos que essas críticas podem ser desenvolvidas de maneira muito mais ampla: Pierre Laffitte, por exemplo, literalmente afirmou que a doutrina do laissez-faire é uma forma de a burguesia justificar seu domínio político e explorar o proletariado, prostituindo a palavra "progresso", reduzida a 1) simples sinônimo mudanças (sociais e, particularmente, tecnológicas) e 2) aumento da produção e estímulo ao consumo (LAFFITTE, 1876). Embora Laffitte em alguns pontos importantes, a despeito de suas próprias afirmações, distanciasse-se de Comte, o fato é que não há motivos para duvidar da mais estrita obediência teórica de Laffitte em relação a Comte nessa questão: afinal de contas, Comte era claro ao criticar a vulgaridade moral e social da burguesia, ou melhor, seu caráter socialmente egoísta e frívolo (COMTE, 1899, p. 157; cf. também LAFFITTE, 1892, p. 42).

Após ter escrito, entre 1851 e 1854, seu Sistema de política positiva, em que sistematiza as perspectivas do Positivismo religioso sobre a sociedade, Comte planejava escrever entre 1856 e 1859 a Síntese subjetiva, em que trataria de algumas questões práticas de que o Positivismo deveria tratar. Em quatro volumes, o primeiro seria dedicado à filosofia matemática (particularmente à Lógica); o segundo e o terceiro, à Moral (ou, contemporaneamente, Psicologia); o quarto, à indústria e às relações industriais. Todavia, Comte morreu em 1857, tendo escrito e publicado apenas o primeiro desses volumes, de tal sorte que um desenvolvimento mais amplo das críticas à Economia Política, das concepções positivistas sobre a economia e as propostas práticas para organização e solução dos problemas econômicos pela pena do próprio Comte não foi possível. Após a morte de Comte, Pierre Laffitte continuou várias das atividades filosóficas do mestre, no sentido de explicar e desenvolver o que A. Comte dissera; para o que nos interessa neste momento e sem

20 Exatamente com esse espírito, não se tornou famosa a declaração de Margareth Thatcher de que a sociedade são apenas indivíduos e empresas? 
pretender esgotar a imensa produção de Laffitte (que se estendeu por quase meio século, de 1857 até 1903, quando morreu), duas obras são úteis: "Le Positivisme et l'Économie Politique”, de 1876, e "De la stabilité de l'équilibre économique”, de 1892. Nelas, após passar em revista os princípios teóricos e epistemológicos que vimos indicando, Laffitte apresenta algumas das soluções positivistas para os problemas econômicos.

Essas soluções são primeiro morais, depois intelectuais e então práticas - mas havendo medidas para essas três etapas. Essa ordem segue um princípio de Comte: primeiro reorganizar as idéias e os hábitos, para então reorganizar as instituições (o que, aliás, é uma outra forma de propor uma separação entre a teoria e a prática). Antes de mais nada, é importante acabar com a distinção moral (mas não a jurídica) entre público e privado: afinal de contas, as ações individuais têm consequiências coletivas e, sendo a propriedade um conceito relativo à sociedade, a posse do capital deve ser avaliada precisamente por essas consequiências.

Dessa forma, a partir dos princípios teóricos indicados até aqui, a noção de "dever" tem que ser associada ao capital e ao seu uso, no lugar da noção de "direito". Comenta Laffitte que o dever é uma função realizada por um órgão livre, ou seja, é o conjunto de responsabilidades morais e cívicas assumidas voluntariamente por um cidadão. A propriedade, percebida de maneira relativa, é privada e sua utilização (social) é avaliada do ponto de vista do bem comum; em particular, a especulação financeira é criticada por Laffitte como socialmente daninha. As mudanças econômicas, devidas ao progresso técnico, não podem ocorrer de supetão: é necessário que os trabalhadores tenham tempo para adaptar-se, o mesmo valendo para as trocas comerciais internacionais: ainda que, regra geral, o livre-comércio deva prevalecer, se dois países estabelecerem um relacionamento econômico que resulte em transtornos sociais em um deles ou em ambos, o livre-comércio é perfeitamente dispensável, podendo-se adotar com plena justificativa as diversas formas de proteção social e econômica. (Essa, aliás, é uma importante aplicação da máxima comtiana segundo a qual o progresso deve submeter-se à ordem.) Dessa forma, muitas das queixas associadas ao capital e à economia industrial pode- 
riam ser ou evitadas ou minimizadas. Da mesma forma, no caso de crises econômicas, o poder Temporal - ou, de maneira mais direta, o Estado - pode e deve intervir para minorar e solucionar os problemas: embora o Estado deva preferencialmente se manter afastado das atividades econômicas, em situações emergenciais programas de obras públicas com o fim de combater o desemprego são aceitáveis e recomendáveis ${ }^{21}$.

\section{Comentários finais}

Neste artigo apresentamos uma série de elementos da teoria sociológica comtiana. Como pretendemos ter demonstrado, essa teoria é de fato sistêmica, totalizante e "transdisciplinar". Procuramos apresentar as críticas de Comte à Economia Política de sua época, esclarecendo-as por meio da apresentação dos elementos teóricos que chamaríamos de "teoria econômica" do fundador do Positivismo.

Indicamos no final da seção anterior algumas medidas práticas para a solução dos problemas econômicos; tais medidas, como se pode perceber, determinam-se em contraposição ao grosso das idéias do liberalismo econômico ${ }^{22}$. O que subjaz a elas é a preocupação com o bem-estar dos cidadãos, que não devem ser percebidos apenas como a realização concreta da idéia de homo œconomicus (ou seja, como produtores e consumidores), mas também, e principalmente, como integrantes totais de "sociedades bem-ordenadas", isto é, de famílias, de pátrias e da Humanidade, em seus aspectos afetivos, intelectuais e práticos. Dito dessa forma geral talvez soe como platitudes caritativas; entretanto, não apenas são princípios

21 É evidente aí a prefiguração de algumas propostas práticas de Keynes e do que se chamou depois de Estado de Bem-Estar Social.

22 Não fosse a limitação de espaço deste artigo, trataríamos também das críticas de Comte aos grupos que ele chamava de "comunistas". Tais grupos não eram os comunistas derivados do marxismo - seriam o que chamamos atualmente, após o Manifesto do Partido Comunista, de "socialistas utópicos" -, mas os comentários que Comte dirigia-lhes poderiam perfeitamente ser dirigidos aos marxistas. Quais essas críticas? Em linhas gerais, as mesmas feitas aos economistas, mas relativamente aos proletários: economicismo, concepção absoluta da sociedade, egoísmo coletivo baseado no número, etc. Para uma apresentação geral desse tema, cf. Lopes (1946) e Lacroix (2003). 
"genéricos" - pois têm, ou podem ter, consequiências teóricas e práticas bastante marcadas e efetivas - como a leitura direta da obra de Comte permite a apreensão de particularidades e detalhes que não caberiam, por motivos óbvios, neste artigo. Em outras palavras, entre outros elementos de evidente atualidade, subjaz uma concepção forte de justiça social (cf. LACERDA, 2008b).

Recebido em 3.7.2009

Aprovado em 14.9.2009

\section{Referências}

ARNAUD, P. Politique d'Auguste Comte. Paris: A. Colin, 1965.

ARON, R. The Industrial Society. Three Essays on Ideology and Development. New York: Simon \& Schuster, 1968.

BEVIR, M. The Logic of the History of Ideas. Cambridge: University of Cambridge, 1999.

COMTE, A. Système de politique positive, ou traité de Sociologie instituant la Religion de l'Humanité. 4 v. Paris: Société Positiviste, 1890.

. Catecismo positivista ou sumária exposição da Religião da Humanidade. $4^{\mathrm{a}}$ ed. Rio de Janeiro: Apostolado Positivista do Brasil, 1934.

. Écrits de jeunesse - 1816-1828. Texts établis par Paulo Carneiro et Pierre Arnaud. Paris: Mouton, 1970.

. Segundo opúsculo (abril de 1820): Sumária apreciação do passado moderno. In: . Opúsculos de filosofia social. São Paulo: USP, 1972a.

. Terceiro opúsculo (maio de 1822): Plano dos trabalhos científicos necessários para reorganizar a sociedade. In: Opúsculos de filosofia social. São Paulo: USP, 1972b.

. Quinto opúsculo (março de 1826): Considerações sobre o poder Espiritual. In: . Opúsculos de filosofia social. São Paulo: USP, 1972c. 
. Physique social. Cours de philosophie positive, leçons 46 à 60. Paris: Hermann, 1975.

GIDDENS, A. \& PIERSON, C. Conversas com Anthony Giddens. Rio de Janeiro: FGV, 2000.

GOUHIER, H. La jeunesse d'Auguste Comte et la formation du Positivisme. V. 2: Saint-Simon jusqu'à la Restauration. Paris: Vrin, 1936.

GRANGE, J. Auguste Comte. La politique et la science. Paris: O. Jacob, 2000.

KREMER-MARIETTI, A. L'économie positive d'Auguste Comte: entre celle de Jean-Baptiste Say et celle de Milton Friedman. Artigo apresentado no Colóquio "La tradition économique française 1848-1939”, realizado em Lyon, entre 2 e 3 de outubro, 1997. Disponível em : http://dogma.free.fr/txt/AKM-AC_economie_positive. htm. Acesso em: 17.mar.2009.

LACERDA, G. B. Dois erros sobre a doutrina política comtiana: "autoritarismo" e "funcionalismo público". Revista Espaço Acadêmico, Maringá, 2008a. Disponível em : http://www.espacoacademico.com. br/087/87lacerda.htm. Acesso em : 21.mar.2009.

. Eqüidade no projeto republicano de Augusto Comte. Artigo apresentado no 6o Encontro da Associação Brasileira de Ciência Política, realizado de 29 de julho a $1^{\circ}$ de agosto, em Campinas (São Paulo). Digit, 2008b. Disponível em: http://201.48.149.88/abcp2008/ arquivos/22_7_2008_17_23_19.pdf. Acesso em: 21.mar.2009.

LACERDA NETO, A. V. A república positivista. Teoria e ação no pensamento político de Augusto Comte. $3^{\mathrm{a}}$ ed. Curitiba: Juruá, 2003.

LACROIX, J. A Sociologia de Augusto Comte (o fundador da Sociologia). Curitiba: Vila do Príncipe, 2003.

LAFFITTE, P. Le Positivisme et l'Économie Politique. $3^{\mathrm{e}}$ éd. Paris : P. Ritti, 1876.

. De la stabilité de l'équilibre économique. Revue Occidentale, Paris, XV année, II série, t. V, n. 4, p. 35-74, juil, 1892.

. Cours de philosophie première. T. II : des lois universelles du monde. Paris: Société Positiviste, 1894. 
. Cours de philosophie première. T. I : théorie positive de l'entendement. Paris : Société Positiviste, 1928.

LOPES, R. P. (Org.). Auguste Comte. Le Prolétariat dans la société moderne. Coll. "Archives positivistes". Paris: Société Positiviste, 1946.

MAUDUIT, R. Auguste Comte et la science économique. Paris: F. Alcan, 1929.

SKINNER, Q. Visions of Politics. V. I: Regarding Method. Cambridge: Cambridge University, 2002.

STEINER, P. La tradition française de critique sociologique de l'économie politique. Revue d'Histoire des Sciences Humaines, v. 17, p. 63-84, mai, 2008.

\section{Abstract \\ Auguste Comte's Critique of Political Economy.}

The purpose of this article is to present Auguste Comte's critique of the Political Economy of his time as well as the proposals for social reform flowing from it. The methodological framework is built up on the categories proposed by the History of Ideas, in particular those of M. Bevir and Q. Skinner. What we can refer to as "Comtian economic theory" can be found in his "Social Statics", in the sections dealing with property and the material elements of society, and in his "Social Dynamics", where reference is made to the interrelationships between political, social and economic changes throughout history. This economic theory establishes dialogs both with liberals and "communists", on the one hand defending the need for property and on the other, arguing for the subordination of property to social needs and providing a severe critique of individualism. The theory has both direct and indirect consequences: on the one hand, society cannot be reduced to the "market" and the State cannot neglect economic fluctuations; on the other hand, the most immediate conflicts of interest between proletarians and "patricians" cannot deny the social origin of wealth, requiring moral and legal measures for the regulation and resolution of these conflicts. In this regard, Comte may be seen as a precursor of the Welfare State, or at least a theoretician of social justice. Keywords: Auguste Comte, Positivism, Sociology, critique of Political Economy, holist methodology, social justice. 
